\title{
Correlation between Theoretical and Experimental Specific Surface Area Estimation for PANI and PANI (Zr) Composite
}

\author{
Tatiana N. Myasoedova ${ }^{1}$, Nina K. Plugotarenko ${ }^{1}$, Tatiana A. Moiseeva ${ }^{1}$, Eugeniy V. Vorobyev ${ }^{1}$, Vera V. \\ Butova $^{2} \&$ Viktor V. Petrov ${ }^{1}$ \\ ${ }^{1}$ Institute of Management in Economical, Ecological and Social Systems, Southern Federal University, \\ Rostov-on-Don, Russia \\ 2 International Research Center "Intellectual Materials", Southern Federal University, Rostov-on-Don, Russia \\ Correspondence: Tatiana N. Myasoedova, Institute of Management in Economical, Ecological and Social \\ Systems, Southern Federal University, Rostov-on-Don, Russia. Tel: 7-863-437-1624. E-mail: \\ tnmyasoedova@sfedu.ru
}

Received: July 16, 2015

Accepted: August 12, 2015

Online Published: November 30, 2015

doi:10.5539/mas.v9n13p133

URL: http://dx.doi.org/10.5539/mas.v9n13p133

\begin{abstract}
Polyaniline (PANI) and polyaniline/Zr (PANI/Zr) powders have been prepared by in situ polymerization method, and the morphology, structure and pore structure are investigated. Quantum-chemical calculations showed that the polyaniline structure formed with zirconium ions is not globular, but fiber-like, and its fiber patterns are characterized by clear orientation of individual fragments Estimation of the theoretical and experimental specific surface area of the PANI/Zr composite is done. It is shown that the most preferred is the fiber-like structure with the specific surface area about $128-162 \mathrm{~m}^{2} / \mathrm{g}$, which stability may be improved by using zirconium (IV) containing substances as a dopant. Experimental specific surface area is 66.8 and $146.05 \mathrm{~m}^{2} / \mathrm{g}$ for PANI and $\mathrm{PANI} / \mathrm{Zr}$, respectively. Correlation between theoretical and experimental specific surface area $\mathrm{PANI} / \mathrm{Zr}$ composite is observed.
\end{abstract}

Keywords: polyaniline, composite, zirconium, specific surface area

\section{Introduction}

Today, there is substantial demand for new materials to create new types of electronic devices: such materials should be characterized by low density, flexibility, low cost and non-toxicity. The said devices are manufactured based on a new class of semiconductor materials, the so-called molecular or organic semiconductors, which contain both low-molecular organic compounds and polymers (Puzar \& Borah, 2013).

Electroconductive polymers constitute a new class of polymers that have appeared quite recently. The use of polymeric materials as carriers of Electroconductive additives was known long ago. Conventional Electroconductive polymeric materials are compounds based on various polymers (thermoplastics and thermosetting plastics) and Electroconductive additives, and are used in thin-film transistors (Kim, et al., 2003], polymer light-emitting diodes (Hameed, et al., 2010), electromagnetic protective coatings (Vovchenko et al., 2012), supercapacitors (Graeme et al., 2011)] and electrochromic devices (Zanarini, et al., 2014). Still, today we already have new materials, in which electrical conductivity is inherent in the very macromolecules or specifically structured supermolecular formations, the so-called "supramolecules". The latter associates with a structure that includes both organic macromolecules and inorganic ions.

Special attention should be paid to polyaniline, a conducting polymer. Nowadays, this polymer is a leader in terms of publications related to both examinations of its structure and properties, and practical application in Electroconductive and anti-corrosion film coatings, electrochromic and electroluminescent devices of various types, as well as in other electronic devices (Cha et al., 2013, Marjanović, 2013).

PANI composites with inorganic additives are also promising materials for electronic application. Such components as metals and their oxides ensured to enhance thermal and chemical stability of the polymer itself as well as to increase the specific surface area. Composite materials consisting of organic and inorganic nanocomponents are in high demand in microelectronics. Such materials are often photosensitive- and are characterized by certain catalytic activity (Alam et al., 2013, Chun-Ling Zhu et al., 2007, Zheng et al., 2011, 
Srivastava et al., 2011).

So, we report in this work the successful fabrication of PANI and PANI/Zr powders prepared by in situ polymerization method and study the influence of zirconium (IV) containing additive on the specific surface area of the composite. Experimental and theoretical methods are involved for evaluating the specific surface area in order to have a possibility to form composites with demanded properties. Zirconium (IV) is interesting due it chemical, thermal stability and excellent ion-exchange behavior that is good for some electrochemical applications.

Also there are no publications were found describing both theoretical and experimental aspects of surface area characterization.

\section{Method}

\subsection{Fabrication of PANI and PANI/Zr}

PANI was synthesized in the following way. Aniline was dissolved in the aqueous hydrochloric acid solution and cooled down to $0^{\circ} \mathrm{C}$. After that, while the mixture was vigorously stirred, aqueous ammonium peroxydisulfate solution was dropwise into it, and the mixture was kept for 30 minutes. As a result of this procedure, dark green precipitate was built up, which was then filtered and thoroughly washed with distilled water.After processing, the precipitate was put into a flask with aqueous ammonia and kept for 48 hours. Further, the mass was filtered and washed with distilled water and acetone and dried at $80^{\circ} \mathrm{C}$.

In order to produce $\mathrm{PANI} / \mathrm{Zr}$ powders, $\mathrm{ZrOCl}_{2} \cdot 8 \mathrm{H}_{2} \mathrm{O}$ dissolved in water was added to aniline in the hydrochloric acid solution. Then, concentrated hydrochloric acid was added in the mixture, and the process is repeated in the manner similar to that followed when producing pure PANI.

\subsection{Evaluation of Specific Surface Area and Surface Morphology}

The specific surface area was determined by applying the BET method (Brunauer-Emmett-Teller) based on the isotherms of physical adsorption of nitrogen at $-196^{\circ} \mathrm{C}$ (Asap 2020). The material was heated and degassed by vacuum force or inert gas purging to remove adsorbed foreign molecules. A controlled inert gas, such as $\mathrm{N}_{2}$, was introduced, and the gas was adsorbed or, alternatively, withdrawn and desorbed. The amount of gas molecules adsorbed or desorbed was determined by the variation in pressure due to the adsorption or desorption of the gas molecules by the material (the adsorbent). Various amounts of gas molecules are adsorbed or desorbed at different doses of the gas (the adsorbate). Knowledge of the area occupied by one adsorbate molecule and the use of an adsorption model allowed for the determination of the total surface area of the material. The Barrett-Joyner-Halenda (BJH) method was used to evaluate the average pore diameter (Barrett et al., 1951)

Surface morphology was characterized by scanning electron microscopy (SEM) (LEO 1560 microscope).

\subsection{Quantum-Chemical Calculations}

Quantum-chemical calculations were done with Gaussian 03 software using B3LYP method and 6-31G** basis, Hartree-Fock energies were evaluated in order to explain the pattern of the PANI/Zr composite powder structure.

\section{Results and Discussion}

\subsection{Study of Surface Morphology}

SEM images of PANI and PANI/Zr were presented in Figure 1. Figure 1 showed that the image of PANI/Zr was similar to that of PANI. The diameter of PANI nanofibers was between 90 and $100 \mathrm{~nm}$. And the diameter of PANI/Zr nanofibers was approximately $40-50 \mathrm{~nm}$. What's more, the surface of PANI/ Zr nanofibers became rougher, as shown in Figure $1 \mathrm{~b}$. Nanofibers with a rough surface were easy to gather into branches, and increased the effective surface area. 


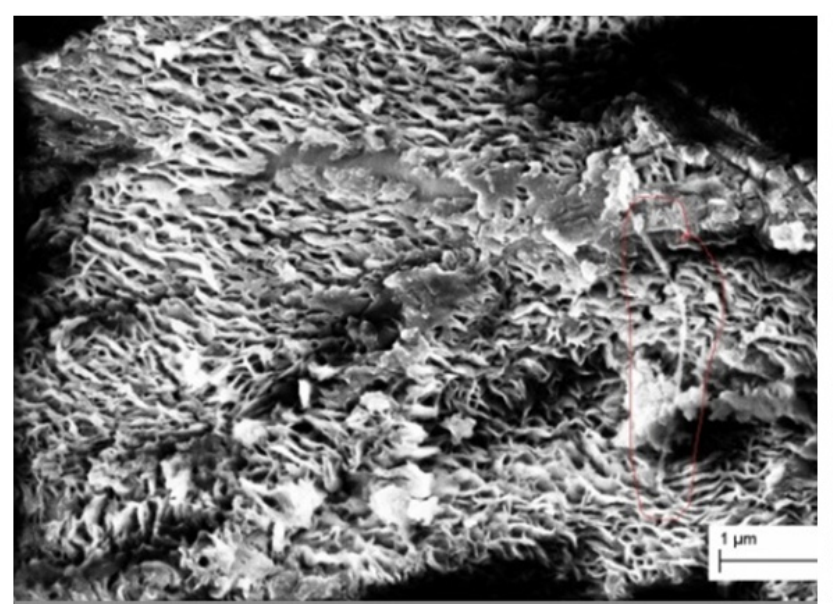

a)

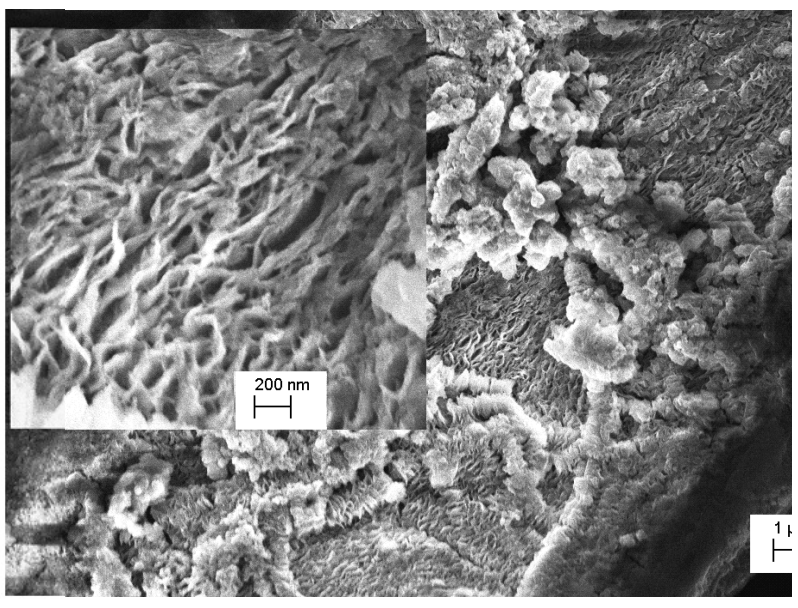

b)

Figure 1. SEM Images of PANI (a) and PANI/Zr (b)

\subsection{Quantum-Chemical Calculations}

To explain the pattern of the PANI/Zr composite powder fiber structure, quantum-chemical calculations in respect of different ways of arrangement of polyaniline fragments (tetramers) with zirconium (IV) ions were performed.

In the first instance, an aniline tetramer was studied, which was characterized by relatively linear chain arrangement (complex 1, Fig 2 a). Another sample under consideration was a twisted aniline tetramer (complex 2, Figure $2 \mathrm{~b}$ ), and the third variant was the most advanced and promising in terms of energy (complex 3, Figure 2 c).

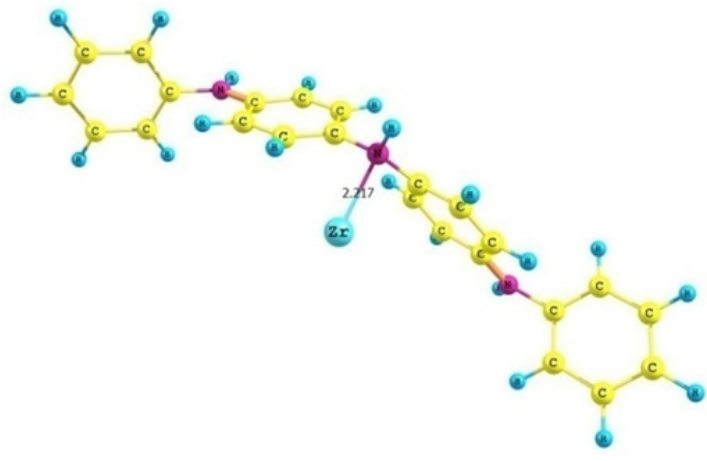

a)

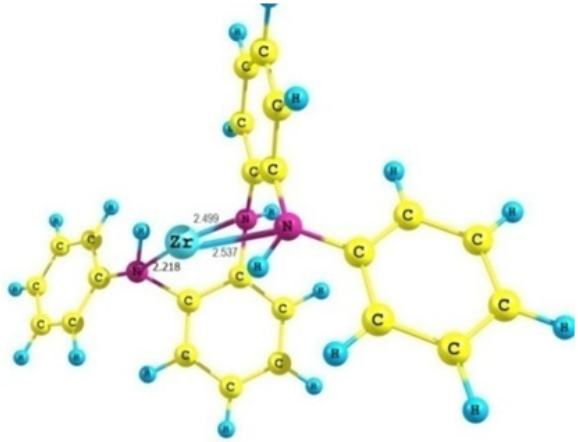

b)

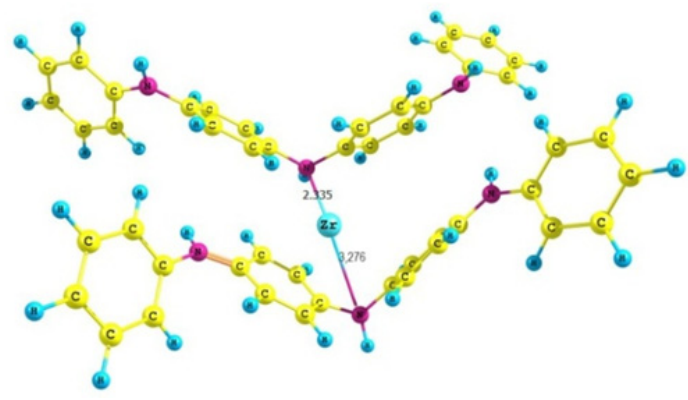

c)

Figure 2. Complexes 1(a); 2 (b); 3 (c) 
The data thus obtained in relation to Hartree-Fock energy of the complexes are summarized in Table 1.

Table 1. Energy of complexes and individual components

\begin{tabular}{cccc}
\hline № & $\mathrm{E}_{\mathrm{HF}}(\mathrm{eV})$ & $\mathrm{E}_{\mathrm{HF}}$ №... $+\mathrm{E}_{\text {tetramer }}(\mathrm{eV})$ & $2 \mathrm{E}_{\text {tetramer }}+\mathrm{E}_{\mathrm{Zr}}{ }^{+2}(\mathrm{eV})$ \\
\hline Complex 1 & -4600.0647 & -5678.4471 & - \\
Complex 2 & -4600.0792 & -5678.4616 & - \\
Complex 3 & -5678.5579 & - & - \\
Aniline Tetramer & -1078.3824 & - & $-5677,9459$ \\
$\mathrm{Zr}^{+2}$ & -3521.1811 & - & \\
\hline
\end{tabular}

As it is evident from the table above, all variants of the complexes formed are still more advantageous in terms of energy than the total energy of an isolated zirconium ion and two polyaniline fragments in the form of tetramers.

Complex 3 is the most favorable: it contains a zirconium ion coordinated between nitrogen atoms of two parallel tetramers. This brings us to an assumption that in case polyaniline is formed with zirconium ions, a number of "zirconium bridges" is built up between polymer molecules, this materially affecting the shape of polymer particles. In particular, as it was observed during the experiment, the polyaniline structure formed with zirconium ions is not globular, but fiber-like, and its fiber patterns are characterized by clear orientation of individual fragments.

\subsection{Evaluation of Specific Surface Area}

According to the obtained results, the specific surface area of polyaniline with a dopant in dependence to geometrical dimensions of the polyaniline structure was predicted. "In-situ" polymerization methods allow forming structures of varied geometry.

The paper shows how functional groups introduced in a polymer affect the density of a PANI-based material. Density of PANI without a dopant amounts to $1.39 \mathrm{~g} / \mathrm{cm}^{3}$. Adding of a metal (zirconium, in our case) makes the material structure heavier (density: $1.52 \mathrm{~g} / \mathrm{cm}^{3}$ ). Studies (Goel et al., 2006, Najim \&Salim, 2014) show dimensions and shapes of the produced PANI-based materials depending on their synthesis process parameters. These are granules $30-150 \mathrm{~nm}$ in diameter, nanofibers 10-100 nm in diameter and nanotubes of 100-300 nm. According to (Goel et al., 2006, Najim \&Salim, 2014) studies, the values of particle radiuses and material density were the inputs for valuing theoretical specific surface area. The specific surface area of the powders was calculated using the following formulas: for granules (hemispherical surface) $-A_{s p}=3 /(\rho \cdot r)$; for nanofibers $-A_{s p}=2 /(\rho \cdot r)$; for nanotubes $\mathrm{A}_{\mathrm{sp}}=2 /\left(\rho \cdot\left(\mathrm{r}_{\mathrm{out}}-\mathrm{r}_{\mathrm{in}}\right)\right)$, where $r$ is the radius of a nanoparticle, $\mathrm{m} ; \rho$ is the material density, $\mathrm{g} / \mathrm{m}^{3}$. The calculation results are presented in Table 2 .

Table 2. Specific Surface Area of Composite PANI-Based Nanomaterials (with dopants)

\begin{tabular}{cccc}
\hline Particle Shape & Particle Radius, $\mathrm{nm}$ & Material Density, $\mathrm{g} / \mathrm{cm}^{3}$ & Specific Surface, $\mathrm{m}^{2} \mathrm{~g}$ \\
\hline Granule & $30-100$ & 1.23 & $81-24$ \\
Granule & $30-100$ & 1.39 & $72-22$ \\
Granule & $30-100$ & 1.52 & $66-20$ \\
$\begin{array}{c}\text { Nanofiber } \\
\text { Nanofiber }\end{array}$ & $10-80$ & 1.23 & $162-40$ \\
Nanofiber & $\begin{array}{l}10-80 \\
10-80\end{array}$ & 1.39 & $144-29$ \\
Nanotube & $\begin{array}{c}\text { out } 100 \\
\text { in } 70\end{array}$ & 1.52 & $128-16$ \\
Nanotube & $\begin{array}{c}\text { out 100 } \\
\text { in 70 }\end{array}$ & 1.39 & 57 \\
Nanotube & $\begin{array}{c}\text { out 100 } \\
\text { in 70 } \\
\text { out 120 } \\
\text { in 100 } \\
\text { out 120 } \\
\text { in 100 } \\
\text { out 120 } \\
\text { in 100 }\end{array}$ & 1.52 & 48 \\
Nanotube & 1.23 & 43 \\
Nanotube & 1.39 & 81 \\
Nanotube & & 1.52 & 72 \\
\hline
\end{tabular}


The active specific surface may either exceed or be smaller than that calculated based on the specific surface geometrical dimensions. It is determined by the particles having functional groups on their surface, presence of pores and supramolecular structure. In our case, the most preferred is the fiber-like structure with the specific surface area about $128-162 \mathrm{~m}^{2} / \mathrm{g}$, which stability may be improved by using zirconium as a dopant.

In order to support the theoretical evaluation, isotherms of adsorption of PANI and PANI/ $\mathrm{Zr}$ powders were studied. The specific surface area of PANI determined by the BET method amounted to $66.8 \mathrm{~m}^{2} / \mathrm{g}$. As it is seen on the pore diameter distribution diagram below, the diameter varies from mesopores $(2 \mathrm{~nm})$ to macropores $(160-170 \mathrm{~nm}$ ) with the peak value falling on macropores and being $115 \mathrm{~nm}$ (Figure 3). The porous structure of PANI will be an added advantage for electron transfer when current is applied to the conductive polymer.

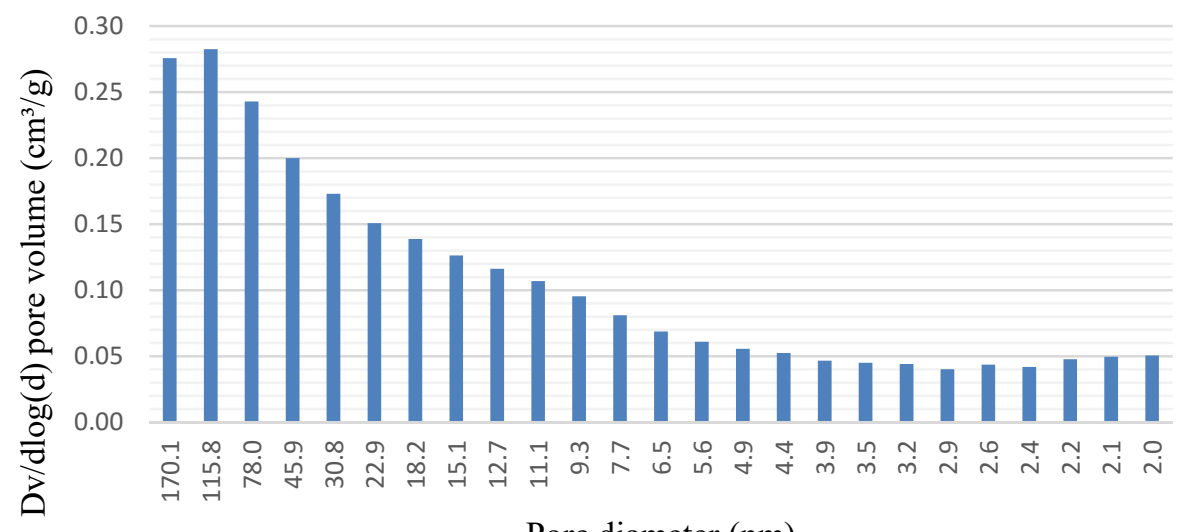

Pore diameter (nm)

Figure 3. Size-Volume Distribution of PANI Pores

The PANI/Zr surface area amounted to $146.05 \mathrm{~m}^{2} / \mathrm{g}$. The isotherm curve is typical of non-porous and macroporous materials (Figure 4). As evidenced by a distinct hysteresis loop, an effect of capillary condensation was here produced. The pore size calculated from the respective adsorption data (Figure 4) made up $8 \mathrm{~nm}$ (Figure 5). Still, no distinct maximum can be observed when making a diagram of pore distribution by sizes, this rendering it difficult to estimate pore sizes by analyzing adsorption data.

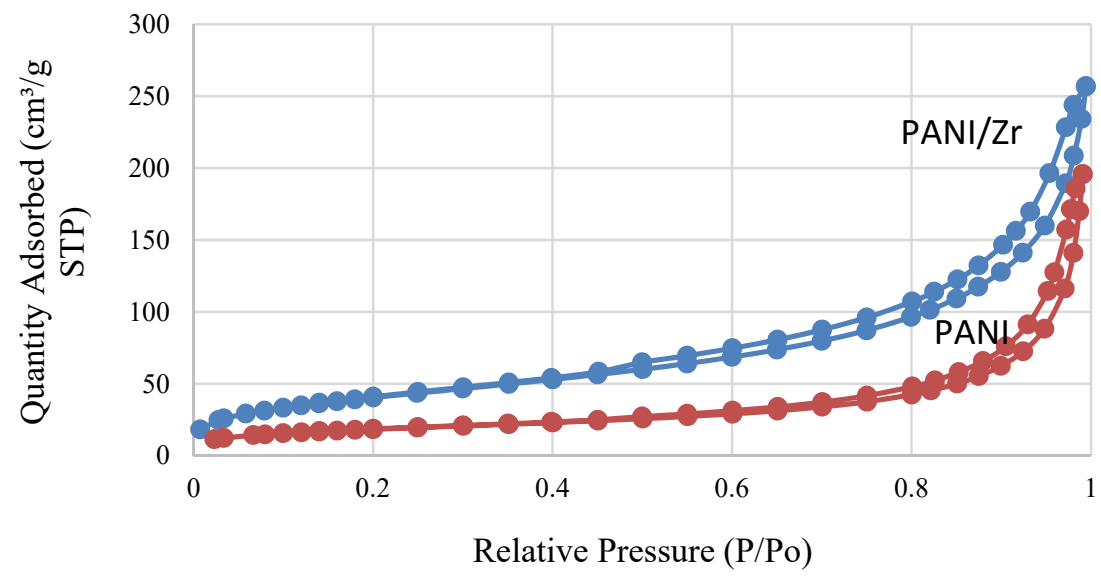

Figure 4. $\mathrm{N}_{2}$ Adsorption/Desorption Isotherms of PANI and PANI/Zr 


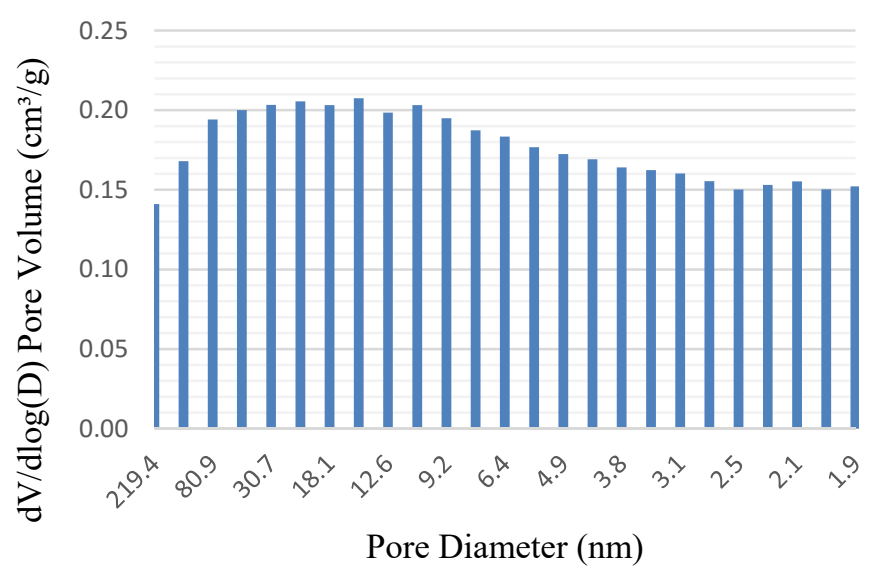

Figure 5. Size-Volume Distribution of PANI/Zr Pores

\section{Conclusion}

After a comparative study as regards the results of estimation of the specific surface was conducted, it became clear that the specific surface values obtained theoretically correlate with those defined by using the BET method. The calculations and measurements performed correspond to the fiber-like shape.

Quantum-chemical calculations showed that the most favourable structure of PANI/Zr composite contains a zirconium (IV) ion coordinated between nitrogen atoms of two parallel tetramers. So a number of "zirconium bridges" is built up between polymer molecules.

PANI and PANI with zirconium are characterized by fiber-like structure. Adding of zirconium let density fibers and makes them thinner and more elastic, this allowing increasing the material specific surface from 66.8 to $146.05 \mathrm{~m}^{2} / \mathrm{g}$. The surface area and porosity of the PANI $/ \mathrm{Zr}$ composite shows that reinforcement of filler into a PANI matrix creates a different phase relative to the matrix materials that differs in its physical properties from the matrix of the conductive polymer.

\section{Acknowledgments}

The work has been financed by the Ministry of Education of Russian Federation (agreement №14.575.21.0103, RFMEFI57514X0103).

The specific surface area of the materials was investigated at the International Research Center "Intellectual Materials" (Russia, Southern Federal University). The materials were prepared at the Center for Collective Usage "Microsystems Technique and Integral Sensory" (Russia, Southern Federal University).

Authors thanks M. Brzhezinskaya and G. Yalovega for SEM investigations conducted at the Helmholtz-Zentrum Berlin für Materialien und Energie.

\section{References}

Alam, M., Ansari, Anees A., Shaik, M. R., \& Alandis, N. M. (2013). Optical and electrical conducting properties of Polyaniline/Tin oxide nanocomposite. Arabian Journal of Chemistry, 6, 341-345. http://dx.doi.org/ 10.1016/j.arabjc.2012.04.021.

Barrett, E. P., Joyner, L. G., \& Halenda, P. P. (1951). The determination of pore volume and area distributions in porous substances. I. computations from nitrogen isotherms. Journal of the American Chemical Society, 73(1), 373-380.

Cha, S., Hong, Y., Yang, J., Maeng, I., Oh, S. J., Jeong, K., \& Choi, H. (2013). Ultrafast Spin-Resolved Spectroscopy Reveals Dominant Exciton Dynamics in Conducting Polymer Polyaniline. Journal of Physical Chemistry: C., 117(39), 20371-20375. http:// dx.doi.org/10.1021/jp408800j

Goel, S, Gupta, A., Singh, K. P., Mehrotra, R., \& Kandpal, H. C. (2006). Optical studies of polyaniline nanostructures. Materials Science and Engineering: A, 443, $71-76$. http://dx.doi.org/10.1016/j.msea.2006.08.035 
Graeme, A., Pon Kao, Best, \& Adam, S. (2011). Conducting-polymer-based supercapacitor devices and electrodes. Journal of Power Sources, 196, 1-12. http://dx.doi.org/10.1016/j.jpowsour.2010.06.084

Hameed, S., Predeep, P., \& Baiju, M. R. (2010). Polymer light emitting diodes - a review on materials and techniques. Reviews on Advanced Materials Science, 26, 30-42.

Kim, J., Hong, Y., \& Kanicki, J. (2003). Amorphous Silicon TFT-Based Active-Matrix Organic Polymer LEDs. IEEE Electron device letters, 24(7), 451-453. http://dx.doi.org/10.1109/LED.2003.814999

Marjanović, G. C. (2013). Recent advances in polyaniline research: Polymerization mechanisms, structural aspects, properties and applications. Synthetic Metals, 177, 1-47. http://dx.doi.org/10.1016/j.synthmet.2013.06.004

Najim, T., \& Salim, T. (2014). Polyaniline nanofibers and nanocomposites: Preparation, characterization, and application for $\mathrm{Cr}(\mathrm{VI})$ and phosphate ions removal from aqueous solution. Arabian Journal of Chemistry, 60, 1-9. http:// dx.doi.org /10.1016/j.arabjc.2014.02.008

Puzari, A., \& Borah, J. P. (2013). Ionic self-assembly and hierarchies of polymeric structures generating nanoscale architecture: opportunities ahead from industrial perspective. Reviews on Advanced Materials Science, 34, 88-106.

Srivastava, S., Kumar K., Singh, V. N., Singh, M., \& Vijay, Y. K. (2011). Synthesis and characterization of $\mathrm{Ti}_{\mathrm{O} 2}$ doped polyaniline composites for hydrogen gas sensing. International Journal of Hydrogen Energy, 36(10), 6343-6355. http:// dx.doi.org/10.1016/j.jijhydene.2011.01.141

Vovchenko, L., Perets, Yu., Ovsienko, Matzui, I., L., Oliynyk, V., \& Launetz, V. (2012). Shielding coatings based on carbon-polymer composites. Surface \& Coatings Technology, 211, 196-199. http://dx.doi.org/10.1016/j.surfcoat.2011.08.018

Zanarini, S., Garino, N., Nair J. R., Francia, C., Wojcik, P. J., Pereira, L., \& Penazzi, N. (2014). Contrast Enhancement in Polymeric Electrochromic Devices Encompassing Room Temperature Ionic Liquids. International Journal of Electrochemical Science, 9, 1650 - 1662.

Zheng, L., Xu, Y., Jin, D., \& Xie, Y. (2011). Polyaniline-intercalated molybdenum oxide nanocomposites: simultaneous synthesis and their enhanced application for supercapacitor. Chemistry-An Asian Journal, 6(6), 1505-1514. http:// dx.doi.org/10.1002/asia.201000770

Zhu, C. L., Chou, S. W., He, S. F., Liao, W. N., \& Chia-Chun, C. (2007). Synthesis of core/shell metal oxide/polyaniline nanocomposites and hollow polyaniline capsules. Nanotechnology, 18(27), 1-6. http://dx.doi.org/10.1088/0957-4484/18/27/275604

\section{Copyrights}

Copyright for this article is retained by the author(s), with first publication rights granted to the journal.

This is an open-access article distributed under the terms and conditions of the Creative Commons Attribution license (http://creativecommons.org/licenses/by/3.0/). 